
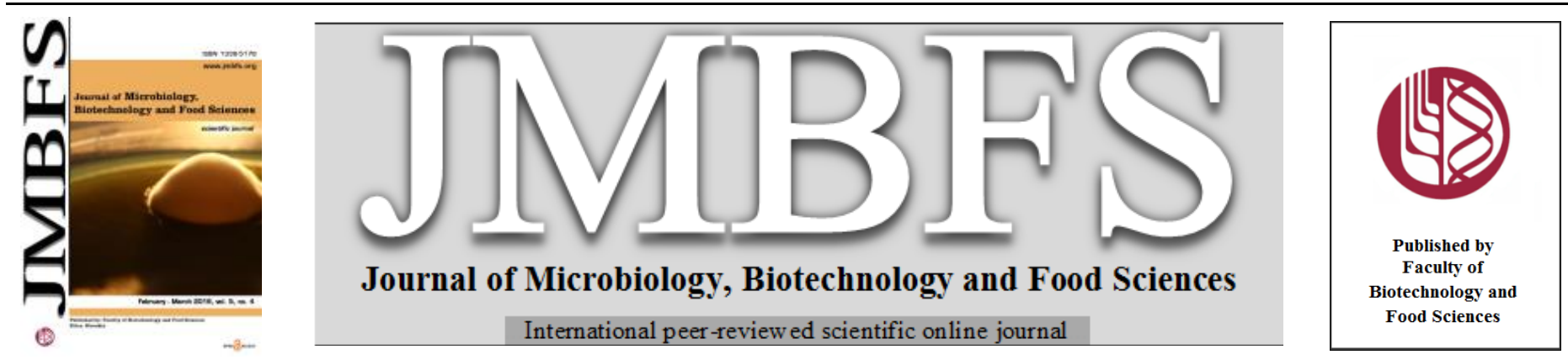

\title{
EFFECT OF THE SINGLE DOSES OF CURCUMIN AND KAINIC ACID ON CHANGES IN THE AMOUNT OF REDUCED GLUTATHIONE IN SELECTED ORGANS OF MICE
}

\author{
Waldemar Szaroma ${ }^{1}$, Henryk Lach $^{2}$, Karol Dziubek ${ }^{1}$, Zofia Goc $*^{1}$ \\ Address(es): Ph.D. Zofia Goc, \\ ${ }^{1}$ Pedagogical University of Cracow, Faculty of Geography and Biology, Department of Animal Physiology and Toxicology, Podbrzezie 3, 31-054 Cracow, Poland, \\ phone number: +48126626693 . \\ ${ }^{2}$ Jozef Dietl Malopolska Higher School in Cracow, Rynek Główny 34, 31-010 Cracow, Poland.
}

*Corresponding author: z.goc@vp.pl

doi: 10.15414/jmbfs.2016.5.4.341-344

ARTICLE INFO

Received 23. 10. 2015

Revised 11. 11. 2015

Accepted 13. 11. 2015

Published 1. 2. 2016

Regular article

open $\partial_{\text {ACCESS }}$

\begin{abstract}
In the present study the effect of various doses administration of curcumin prior to the injection of kainic acid (KA) on the changes in the content of reduced glutathione (GSH) in selected organs of the male white mice were investigated. Animals were conducted in five groups: one control group, four experimental groups. The first experimental group received a single intraperitoneal injection of KA (12 $\mathrm{mg} / \mathrm{kg} \mathrm{b}$. w.). The second, third and the fourth experimental group were administered intraperitoneally curcumin at doses of 50, 100 and $200 \mathrm{mg} / \mathrm{kg}$ b. w. 30 minutes before the injection of KA. In the brain, liver, kidneys, pancreas and spleen of the mice GSH was determined. Administration of KA resulted in a significant change in the amount of GSH in all the examined organs of mice. Injections of curcumin and then KA, caused an increase in GSH compared to a group of animals which received only KA. This increase was not significant only in the group which received curcumin in the lowest dose. Results suggest that curcumin has antioxidant properties because advantageously affected changes in the amount of GSH, and thus the size of the oxidative stress induced by KA.
\end{abstract}

Keywords: Curcumin, kainic acid, mouse, reduced glutathione

\section{INTRODUCTION}

Curcumin (IE, 6E)-1,7-bis (4-hydroxy-3-methoxyphenyl)-1,6-heptadiene-3,5dione, also known as diferuloilmetan is a polyphenol present in turmeric rhizomes (Curcuma longa L.), with the content of $5-10 \%$ of dry mass. In the Eastern medicine it has been used for centuries for medical purposes. Only recent research begun to investigate its medicinal properties (Sreejayan and Rao, 1997). Many studies have succeeded in the following process of curcumin biotransformation in the body and suggested therapeutic effectiveness against many diseases, including diabetes, asthma, allergies, arthritis, atherosclerosis, neurodegenerative diseases and other chronic diseases such as cancer (Ireson $\boldsymbol{e}$ al., 2002; Duvoix et al., 2005; Anand et al. 2007; Darvesh et al.,2012; Kapakos et al., 2012). Due to the potential applicability of curcumin for therapeutic purposes, many research studies focus on understanding of the mechanisms of antioxidant curcumin activity of after the kainic acid (KA) administration induced excitotoxicity (Sumanont et al., 2006; Shin et al., 2007; Sumanont et al., 2007; Gupta et al. 2009).

Kainic acid (KA) is a specific agonist of ionotropic glutamate receptors (iGluRs) and a strong neurotoxin (Vincent and Mulle, 2009). KA acts on kainate receptors (KARs) in the central nervous system (CNS) and imitates the excitotoxic action of glutamate in models of neurodegenerative disorders. The KA binding to KARs receptors causes a number of cellular events, including the influx of $\mathrm{Ca}^{2+}$ into cells, the production of reactive oxygen species (ROS) and reactive nitrogen species (RNS), which leads to the mitochondrial dysfunction, apoptosis of neurons and necrosis (Wang et al., 2005).

Excitotoxicity is considered to be an important mechanism involved in various neurodegenerative diseases in the CNS, such as, for example, Alzheimer's disease (AD), Parkinson's (PD), amyotrophic lateral sclerosis (ALS) and epilepsy (Frantseva et al., 2000; Johnson et al., 2009; Zheng et al., 2011; Mitra et al., 2013). However, the mechanism via which excitotoxicity is involved in the induction of the disease remains unclear (Zheng et al., 2011). Accordingly, many researchers are interested in the question of whether it is possible to reduce excitotoxicity and its effects, not only in the CNS, but also in other animal organs.

Reduced glutathione (GSH) is the basic non-protein thiol in a cell displaying multiple properties (Dringer et al., 2000; Meister, 1981). It is considered that it modulates the level of ROS and thus, participates in the cellular response to oxidative stress (Gorrini et al., 2013; Presnell, 2013). Therefore, the content of GSH in the cell, besides the physiological values, may be a useful indicator of the level of oxidative stress (Pastore et al., 2003). Hence the question of whether curcumin, which is ascribed antioxidant properties, will affect the changes in the amount of GSH, and, at the same time, in the size of the oxidative stress induced by KA. In the present experiment, we evaluate the amount of GSH in the brain, liver, kidney, pancreas and spleen of mice after the injection of KA alone, as well as after the administration of various doses of curcumin and additional KA after 30 minutes.

\section{MATERIAL AND METHODS}

In the experiment consisting of one control group and four experimental groups the total of 40 four-month male white mouse of Swiss strain with an average body weight of $27 \mathrm{~g}$ was used. All animals were obtained from the experimental research laboratory of the Department of Animal Physiology and Toxicology, Institute of Biology, Pedagogical University of Cracow. All mice of the control group and the experimental groups included 8 individuals each; animals were kept in suitable cages with full access to the standard food and water throughout the experiment. The lighting was regulated in LD 12:12 cycle (light phase starting at $8^{00}$ till $\left.20^{00}\right)$. The breeding room was soundproof, the average temperature was $20^{\circ} \mathrm{C} \pm 2{ }^{\circ} \mathrm{C}$ and the relative humidity equaled $55 \% \pm 5 \%$.

Animals of the control group received at $8^{00}$ (at the start of the light phase of LD $12: 12$ ) a $0.9 \%$ solution of $\mathrm{NaCl}$ (Polfa) in the amount of $0.3 \mathrm{ml}$ as an intraperitoneal injection. In the first group of experimental mice kainic acid (KA) (Sigma, St. Louis, MO) was also intraperitoneally administered at the same time of day, i.e. at $8^{00}$ at a dose of $12 \mathrm{mg} / \mathrm{kg}$ body weight (b.w.) dissolved in normal saline ( $\mathrm{pH}$ adjusted to 7.4 with sodium hydroxide). In turn, the second group of experimental animals received at $8^{00}$, curcumin (Sigma, St Louis, MO) dissolved in diamethyl sulfoxide (Sigma, St. Louis, MO) at a dose of $50 \mathrm{mg} / \mathrm{kg}$ b.w. as an intraperitoneal injection and after 30 mins - KA, also as an intraperitoneal injection at a dose of $12 \mathrm{mg} / \mathrm{kg}$ b.w. Mice of the third experimental group received at $8^{00}$, an intraperitoneal injection of curcumin at $100 \mathrm{mg} / \mathrm{kg}$ b.w. and after 30 mins KA was added in the amount of $12 \mathrm{mg} / \mathrm{kg}$ b.w. Animals of the fourth experimental group received at $8^{00}$ intraperitoneally curcumin at a dose of $200 \mathrm{mg} / \mathrm{kg}$ b.w. and, after $30 \mathrm{mins}, \mathrm{KA}-$ at a dose of $12 \mathrm{mg} / \mathrm{kg}$ b.w. Mice of the control group were decapitated $4 \mathrm{hrs}$ after the administration of physiological 
saline, and all the experimental groups - four hours after the injection of kainic acid. Initially, the animals were put into a state of deep anesthesia by intramuscular administration of vetbutal (Biowet, Poland) in the amount of 35 $\mathrm{mg} / \mathrm{kg}$ b.w. diluted solution of $\mathrm{NaCl} 0.9 \%$ (Polfa).

Weighed organs were homogenized in a homogenizer with a Teflon plunger in 6 $\mathrm{ml}$ of, cooled up to $4^{\circ} \mathrm{C}, 0.1 \mathrm{M}$ phosphate buffer, $\mathrm{pH} 7.4$, containing $10 \mathrm{mM}$ EDTA. The homogenates were centrifuged in a centrifuge MPW-365 at $4{ }^{\circ} \mathrm{C}$ for 15 minutes at $15000 \mathrm{~g}$. Thus obtained supernatants of homogenates of brain, liver, kidney, pancreas and spleen were then deproteinized by adding $500 \mu \mathrm{l}$ of supernatant into $500 \mu \mathrm{TCA}$ and $500 \mu \mathrm{l}$ EDTA. This mixture was put in the fridge at $4^{\circ} \mathrm{C}$ for 10 minutes, then centrifuged for $5 \mathrm{~min}$ at $5000 \mathrm{~g}$ at $4^{\circ} \mathrm{C}$. In the obtained post-centrifugation deproteinized supernatants of brain, liver, kidney, pancreas and spleen GSH concentration was determined using the Ellman's method (Ellman, 1959).

From the results of GSH content in the brain, liver, kidney, pancreas and spleen in the control and experimental groups, arithmetic means and standard deviations were calculated. Percentage changes in the amount of GSH in the experimenta groups as compared to the control group were calculated. The results were verified with the use of the statistical test $t$ "Student - Gosset". All statistica calculations of the data obtained during experiments were done with the computer program STATISTICA 9 (StatSoft, Cracow, Poland)

\section{RESULTS AND DISCUSSION}

\section{Results}

The obtained results of the experiment on GSH determination in the brain, liver, kidney, pancreas and spleen after 4 hours of kainic acid (KA) intraperitoneal administration to the four-week-old male mice, in the amount of $12 \mathrm{mg} / \mathrm{kg}$, of different doses of curcumin $(50,100$, and $200 \mathrm{mg} / \mathrm{kg}$. b.w.), and, after 30 minutes, of additional KA are shown in Figure 1-5.

In the mouse brain, in relation to the control values 4 hours after the KA injection, a statistically significant decrease in the GSH content was found ( $p$ $<0.001 ; 54.92 \%$ ) (Fig. 1). After the intraperitoneal injection of curcumin at a dose of $50 \mathrm{mg} / \mathrm{kg}$ b.w. and KA after $30 \mathrm{mins}$ a slight increase in the content of GSH $(6.38 \%)$ relative to the group after KA injection but not statistically significant (Fig. 1) was observed. In the animals that received intraperitoneal curcumin at the dose of 100 and $200 \mathrm{mg} / \mathrm{kg}$ b.w. and KA after $30 \mathrm{mins}$ statistically significant $(\mathrm{p}<0.001)$ increase in the concentration of GSH in the brain, $30.39 \%$ and $63.87 \%$, respectively were found (Fig. 1).

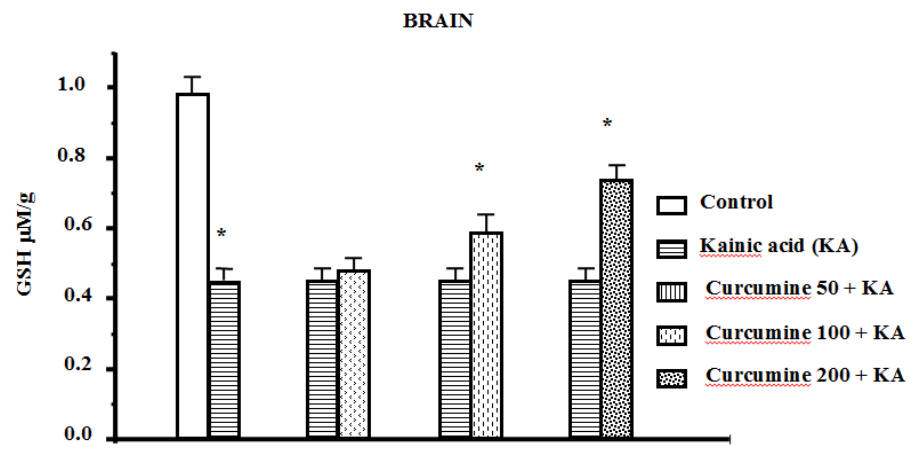

Figure 1 The level of reduced glutathione (GSH) in the brain of control and experimental male mice 4 hours after the intraperitoneal administration of kainic acid (KA) at a dose of $12 \mathrm{mg} / \mathrm{kg}$ b.w., (I experimental group), curcumin at a dose of $50 \mathrm{mg} / \mathrm{kg}$ b.w., and after $30 \mathrm{~min}$. KA (experimental group II), curcumin at a dose of $100 \mathrm{mg} / \mathrm{kg}$ b.w., and KA (III experimental group), curcumin at a dose of $200 \mathrm{mg} / \mathrm{kg}$ b.w., and KA (IV experimental group). * - Indicates statistically significant at $\mathrm{p}<0.001$

In the liver, as compared to the control values, 4 hours after the injection of KA, statistically significant ( $\mathrm{p}<0.001$ ) decrease in GSH concentration was observed (Fig. 2). This decrease equalled $40.93 \%$. In the group of animals that received curcumin at a dose of $50 \mathrm{mg} / \mathrm{kg}$ b.w. followed by additional KA after 30 mins, an increase in GSH level reached $6.14 \%$ which was statistically insignificant (Fig. 2). In turn, the mice after the injection of curcumin in the amount of 100 and 200 $\mathrm{mg} / \mathrm{kg}$ b.w., followed by KA administration after $30 \mathrm{mins}$, showed a significant increase in the concentration of this tripeptide in the liver; $19.03 \%$ and $48.24 \%$, respectively.

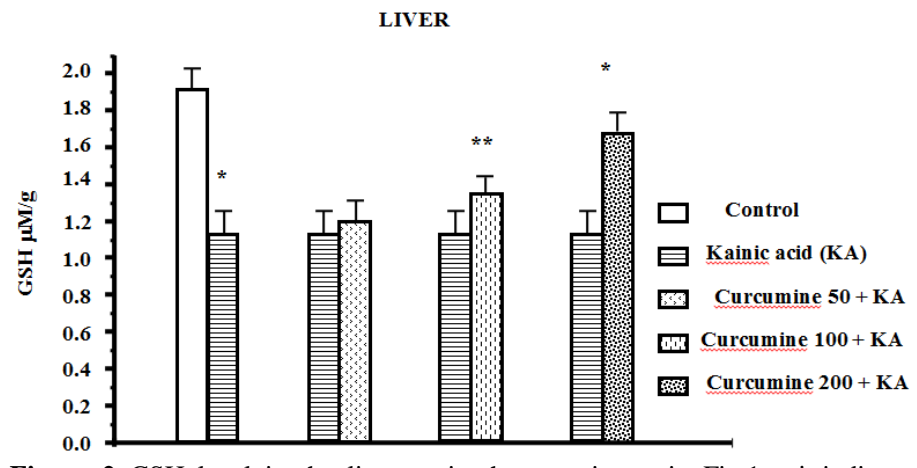

Figure 2 GSH level in the liver as in the experiment in Fig.1. * indicates statistically significant at $\mathrm{p}<0.001$ and $* *$ indicates $\mathrm{p}<0.01$

In kidneys of animals which received the KA, after 4 hours, the concentration of the tested tripeptide was statistically significant ( $\mathrm{p}<0.001)$, reduced as compared to the control by $54.62 \%$ (Fig. 3). After the intraperitoneal injection of curcumin at $50 \mathrm{mg} / \mathrm{kg}$, and post additional KA implementation after $30 \mathrm{mins}$, slightly increased GSH concentration occurred as compared to that obtained from animals receiving only KA. This increase was $8.83 \%$ and was statistically insignificant. In mice treated with curcumin intraperitoneally at 100 and $200 \mathrm{mg} / \mathrm{kg}$, followed by additional KA administration after 30 mins a statistically significant (p<0.001) increase in GSH levels, respectively $31.73 \%$ and $69.01 \%$ (Fig. 3) was detected.

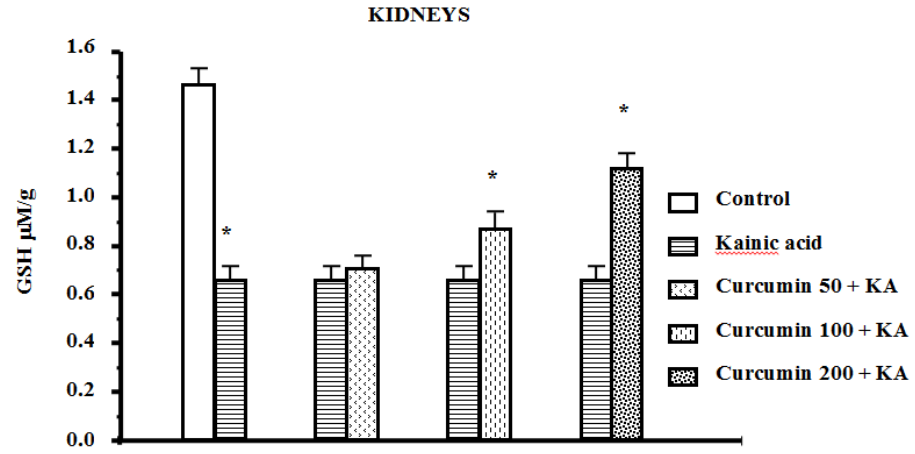

Figure 3 GSH level in the kidneys as in the experiment in Fig.1. * indicates statistically significant at $\mathrm{p}<0.001$ and $* *$ indicates $\mathrm{p}<0.01$

In male mice, 4 hours after the KA injection, statistically significant ( $p<0.001$ ) decrease of GSH level was found in the pancreas. This reduction amounted to $31.35 \%$ (Fig. 4). The animals treated with curcumin $(50 \mathrm{mg} / \mathrm{kg} \mathrm{b.m}$.) followed by additional KA administration after 30 mins, showed an increase in the GSH levels of $6.14 \%$ as compared to animals that received KA only. This increase was statistically insignificant (Fig. 4). Conversely, a statistically significant $(\mathrm{p}<0.001)$ increase in the concentration of GSH in the pancreas by $33.09 \%$ and $58.88 \%$, respectively was recorded in mice that received curcumin at higher doses and KA after 30 mins (Fig. 4).

PANCREAS

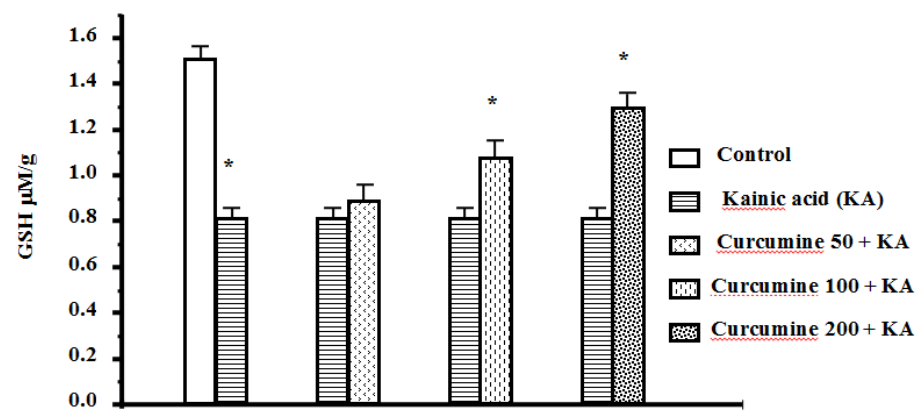

Figure 4 GSH level in the pancreas as in the experiment in Fig.1. * indicates statistically significant at $\mathrm{p}<0.001$ and $* *$ indicates $\mathrm{p}<0.01$

In the spleen, compared to the values in the control animals, 4 hours after KA injection, a statistically significant $(\mathrm{p}<0.001)$ decrease in GSH concentration was found (Fig. 5). This decrease was $43.43 \%$. After the intraperitoneal injection of curcumin at $50 \mathrm{mg} / \mathrm{kg}$ b.w. and KA after $30 \mathrm{mins}$, statistically insignificant slight increase of GSH concentration (7.63\%) was observed as compared to the animals 
treated with KA alone. In mice, after the injection of curcumin in the amount of 100 and $200 \mathrm{mg} / \mathrm{kg}$ b.w., followed by additional KA administration after $30 \mathrm{mins}$, significant increase $(\mathrm{p}<0.001$ ) of this tripeptide level, $19.03 \%$ and $48.24 \%$ respectively was detected (Fig. 5).

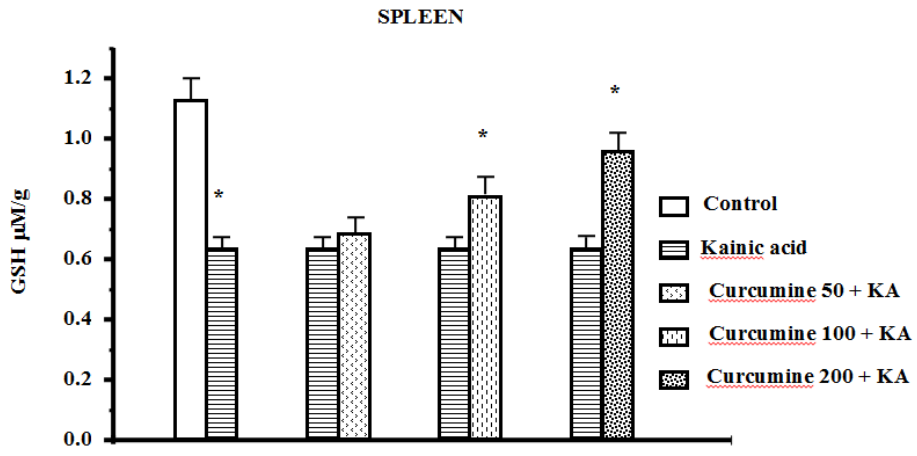

Figure 5 GSH level in the spleen as in the experiment in Fig.1. * indicates statistically significant at $\mathrm{p}<0.001$ and $* *$ indicates $\mathrm{p}<0.01$

\section{DISCUSSION}

The obtained results show that the administration of the KA caused statistically significant reduction in the amount of GSH in all organs of the examined mice. After the administration of curcumin, followed by additional KA administration after 30 mins, there was a smaller decrease in the amount of GSH in relation to the group of animals which received KA. The decrease in the amount of GSH was respectively smaller when before the KA application higher doses of curcumin were used.

After KA administration, it binds to KARs receptors that are present on neurons and microglia. This leads to membrane depolarization, rapid influx of $\mathrm{Ca}^{2+}$ into cells (Vincent and Mulle, 2009), activation of $\mathrm{Ca}^{2+}$-dependent enzymes and the production of ROS and RNS (Kew and Kemp, 2005). Excess of $\mathrm{Ca}^{2+}$, ROS and RNS results in mitochondrial dysfunction and fragmentation of nuclear DNA (Collingridge et al., 2009). Alternatively, intense $\mathrm{Ca}^{2+}$ overload can directly cause mitochondrial swelling and damage, resulting in cell death (Wang $\boldsymbol{e t}$ al. 2005). Following the KA administration, an increased amount of substances reacting with thiobarbituric acid and a reduction of the total antioxidant status (TAS) in the brain of rats were observed. This indicates the presence of oxidative stress in excitotoxicity (Swamy et al., 2009). The presence of such stress after KA is confirmed, also in the present experiment, changes in the amount of GSH not only in the brain but also in the liver, spleen and kidney of mice. Similar changes in the amount of GSH in the organs of mice post KA administration were also observed in earlier experiments (Szaroma et al., 2012).

GSH is synthesized in its reduced form and then converted to the oxidized form by the formation of intramolecular disulfide bond. The basic function of glutathione is to maintain redox balance of the cells, reducing the oxidized particles and the detoxification of ROS, xenobiotics and heavy metals ( $Y \mathbf{u}$ and Zhou, 2007). GSH by a free thiol group, directly reduces the oxidized molecules. It is a coenzyme of certain antioxidant enzymes such as glutathione peroxidases and glutathione transferases (Avery and Avery, 2001; Garcerá et al., 2006; Lillig et al., 2008). Undoubtedly, GSH is the most important non-enzymatic antioxidant in the body. This peptide is present in every cell of the body, particularly rich in its resources are kidneys, liver, brain and spleen.

GSH directly reacts with radicals in non-enzymatic reactions and is an electron donor in the reduction of superoxide by glutathione peroxidase (Wefers and Sies, 1983). The product of oxidation is glutathione disulfide (GSSG) which is re-reduced by glutathione reductase to GSH (Dringen et al., 2000). Severa studies have shown that the amount of GSH significantly decreased in ischemia (Cooper et al., 1980), after the supply of ethanol (Calabrese et al., 1998) or compounds with very strong oxidizing properties. Thus, it suggested that the amount of GSH may be one of the markers of oxidative stress and damage to organs (Bukowska, 2004; Bukowska and Kowalska, 2004).

The reduction of GSH post KA administration, found in the current experiment, confirms the data cited by many authors that GSH plays a key role in the adaptation of the cells to cell stress induced by ROS and RNS. The decrease in GSH concentration after the administration of KA can induce not only a reduction in GSH synthesis, but also increase its consumption in the removal of ROS and RNS (Swamy et al., 2009).

The doses of curcumin used in the present experiment inhibited the decrease in the amount of GSH caused by the administration of KA. As already mentioned curcumin is one of the polyphenolic compounds with antioxidant properties (Giovannini et al., 2006). Curcumin in micro and millimolar concentration is an effective scavenger of free radicals, such as superoxide anion, hydrogen peroxide and nitric oxide. This compound limits lipid peroxidation and reduced levels of oxidized proteins. Curcumin is capable of maintaining cell status of antioxidant enzymes such as superoxide dismutase (SOD), catalase (CAT), glutathione peroxidase (GSH-Px), and increases the concentration of GSH. Besides antioxidative properties, it also possess anti-inflammatory ones (Rahman, 2006) It is suggested that curcumin increases the level of cellular GSH and induces the de novo synthesis of GSH, by stimulating the activity and gene expression ligase $\gamma$-glutamyl-cysteine (GCL). GCL is an important step of adjusting the speed of the process (Zheng $\boldsymbol{e t}$ al., 2007). Moreover, it has been shown to expression of the gene besides ligase $\gamma$-glutamyl-cysteine and increased GSH synthesis that curcumin, in appropriate dose, is cytoprotective because of its strong antioxidant activity and the ability to engage with GSH (Donatus et al., 1990).

\section{CONCLUSION}

Results of this study describe that curcumin is a potent antioxidant and may protect the organs of the tested mice against oxidative stress induced by the administration of KA. It can be concluded that all doses of curcumin increase the percentage of GSH level in selected tissues to protect against the harmful effects of KA. Supplementing with turmeric may therefore be important research for more research into comprehensive action of the substance and its use in treating diseases.

\section{REFERENCES}

Anand, P., Kunnumakkara, A. B., Newman, R. A., Aggarwal, B. B. (2007) Bioavailability of curcumin: problems and promises. Moecular Pharmaceutics, 4, 807-18. http://dx.doi.org/10.1021/mp700113r

Avery, A. M., Avery, S. V. (2001). Saccharomyces cerevisiae expresses three phospholipid hydroperoxide glutathione peroxidases. Journal of Biological Chemistry, 276, 33730-33735. http://dx.doi.org/10.1074/ibc.m105672200

Bukowska, B. (2004). 2,4,5-T and 2,4,5-TCP induce oxidative damage in human erythrocytes: role of glutathione. Cell Biology International, 28, 557-563. http://dx.doi.org/10.1016/j.cellbi.2004.04.013

Bukowska, B., Kowalska, S. (2004). Phenol and catechol induce prehemolytic and hemolytic changes in human erythrocytes. Toxicology Letters, 152, 73-84 http://dx.doi.org/10.1016/j.toxlet.2004.03.025

Calabrese, V., Renis, M., Calderone, A., Russo, A., Reale, S., Barcellona, M. L. Rizza,V. (1998). Stress proteins and SH-groups in oxidant-induced cellular injury after chronic ethanol administration in rat. Free Radical Biology and Medicine, 24, 1159-1167. http://dx.doi.org/10.1016/s0891-5849(97)00441-3

Collingridge, G. L., Olsen, R. W., Peters, J., Spedding, M. (2009). A nomenclature for ligand-gated ion channels. Neuropharmacology, 56, 2 -5. http://dx.doi.org/10.1016/j.neuropharm.2008.06.063

Cooper, A. J., Pulsinelli, W. A., Duffy, T. E. (1980). Glutathione and ascorbate during ischemia and postischemic reperfusion in rat brain. Journal of Neurochemistry, $\quad 35, \quad 1242-1245 . \quad$ http://dx.doi.org/10.1111/j.14714159.1980.tb07882.x

Darvesh, A. S., Carroll, R. T., Bishayee, A., Novotny, N. A., Geldenhuys, W. J., Van Der Schyf, C. J. (2012). Curcumin and neurodegenerative diseases: a perspective. Expert Opinion on Investigational Drugs, 21, 1123-1140. http://dx.doi.org/10.1517/13543784.2012.693479

Donatus, I. A., Sardjoko, A., Vermeulen, N. P.(1990). Cytotoxic and cytoprotective activities of curcumin. Effects on paracetamol-induced cytotoxicity, lipid peroxidation and glutathione depletion in rat hepatocytes. Biochemical Pharmacology, 39, 1869-1875. http://dx.doi.org/10.1016/00062952(90)90603-i

Dringen, R., Gutterer, J. M., Hirrlinger, J. (2000). Glutathione metabolism in brain. European Journal of Biochemistry, 267, 4912-4916. http://dx.doi.org/10.1046/j.1432-1327.2000.01597.x

Duvoix, A., Blasius, R., Delhalle, S., Schnekenburger, M., Morceau, F., Henry, E., Dicato, M., Diederich, M. (2005). Chemopreventive and therapeutic effects of $\begin{array}{llll}\text { curcumin. } & \text { Cancer } & \text { Letters, } & \text { 223, }\end{array}$ http://dx.doi.org/10.1016/j.canlet.2004.09.041

Ellman, G. L. (1959). Tissue sulfhydryl groups. Archives of Biochemistry and Biophysics, 82, 70-77. http://dx.doi.org/10.1016/0003-9861(59)90090-6

Frantseva, M. V., Perez Velazquez, J. L., Tsoraklidis, G., Mendonca, A. J., Adamchik, Y., Mills, L. R., Carlen, P. L., Burnham, M. W. (2000). Oxidative stress is involved in seizure-induced neurodegeneration in the kindling model of epilepsy. Neuroscience, 97, 431-435. http://dx.doi.org/10.1016/s03064522(00)00041-5

Garcerá, A., Barreto, L., Piedrafita, L., Tamarit, J., Herrero, E. (2006) Saccharomyces cerevisiae cells have three omega class glutathione S-transferases acting as 1-Cys thiol transferases. The Biochemical journal, J. 398, 187-196. http://dx.doi.org/10.1042/bj20060034

Giovannini, C., Filesi, C., D'archivio, M., Scazzocchio, B., Santangelo, C., Masella, R. (2006). Polifenoli e defense antiossidanti endogene: effetti sul glutatione e sugli enzimi ad esso correlate. Annali dell'Istituto Superiore di Sanità, 42, 336-347.

Gorrini, Ch., Harris, I. S., Mak, T. W. (2013). Modulation of oxidative stress as an anticancer strategy. Nature Reviews Drug Discovery, 12, 931-947. http://dx.doi.org/10.1038/nrd4002

Gupta, Y. K., Briyal, S., Sharma, M. (2009). Protective effect of curcumin against kainic acid induced seizures and oxidative stress in rats. Indian Journal of 
$\begin{array}{lll}\text { Physioogy } \quad \text { and } & \text { 39-46. }\end{array}$ http://dx.doi.org/10.1016/j.euroneuro.2005.07.004

Ireson, C. R., Jones, D. J., Orr, S., Coughtrie, M. W., Boocock, D. J., Williams, M. L., Farmer, P. B., Steward, W. P., Gescher, A. J. (2002). Metabolism of the cancer chemopreventive agent curcumin in human and rat intestine. Cancer Epidemiology, Biomarkers \& Prevention, 11, 105-111.

Johnson, K. A., Conn, P. J., Niswender, C. M. (2009). Glutamate receptors as therapeutic targets for Parkinson's disease. CNS \& Neurological Disorders Drug Targets, 8, 475-491. http://dx.doi.org/10.2174/187152709789824606

Kapakos, G., Youreva, V., Srivastava, A. K. (2012). Cardiovascular protection by curcumin: molecular aspects. Indian Journal of Biochemistry and Biophysis, 49, 306-315.

Kew, J. N., Kemp, J. A. (2005). Ionotropic and metabotropic glutamate receptor structure and pharmacology. Psychopharmacology, 179, 4-29. http://dx.doi.org/10.1007/s00213-005-2200-z

Lillig, C. H., Berndt, C., Holmgren, A. (2008). Glutaredoxin systems. Biochimica $\begin{array}{llll}\text { et Biophysica 178, } & \text { 1304-1317. }\end{array}$ http://dx.doi.org/10.1016/j.bbagen.2008.06.003

Meister, A. (1981). Metabolism and functions of glutathione. Trends in Biochemical Sciences, 6, 231-234. http://dx.doi.org/10.1016/09680004(81)90084-0

Mitra, N. K., Goh, T. E., Bala Krishnan, T., Nadarajah, V. D., Vasavaraj, A. K. Soga, T. (2013). Effect of intra-cisternal application of kainic acid on the spinal cord and locomotor activity in rats. International Journal of Clinical and Experimental Pathology, 6, 1505-1515.

Pastore, A., Federici, G., Bertini, E., Piemonte, F. (2003). Analysis of glutathione: implication in redox and detoxification. Clinica Chimica Acta, 333, 19-39. http://dx.doi.org/10.1016/s0009-8981(03)00200-6

Potter, P. E. (2013). Curcumin: a natural substance with potential efficacy in Alzheimer's disease. Journal of Experimental Pharmacology, 5, 23-31. http://dx.doi.org/10.2147/jep.s26803

Presnell, C. E., Bhatti, G., Numan, L. S., Lerche, M., Alkhateeb, S. K., Ghalib, M., Shammaa, M., Kavdia, M. (2013). Computational insights into the role of glutathione in oxidative stress. Current Neurovascular Research,10, 185-194. http://dx.doi.org/10.2174/1567202611310020011

Rahman, I., Biswas, S. K., Kirkham, P. A. (2006). Regulation of inflammation and redox signaling by dietary polyphenols. Biochemical Pharmacology, 72 , 1439-1452. http://dx.doi.org/10.1016/j.bcp.2006.07.004

Shin, H. J., Lee, J. Y., Son, E., Lee, D. H., Kim, H. J., Kang, S. S., Cho, G. J., Choi, W. S., Roh, G. S. (2007). Curcumin attenuates the kainic acid-induced hippocampal cell death in the mice. Neuroscience Letters, 416, 49-54. http://dx.doi.org/10.1016/j.neulet.2007.01.060

Sreejayan, N., Rao, M. N. (1997). Nitric oxide scavenging by curcuminoids Journal of. Pharmacy and Pharmacology, 49, 105-107. http://dx.doi.org/10.1111/j.2042-7158.1997.tb06761.x

Sumanont, Y., Murakami, Y., Tohda, M., Vajragupta, O., Watanabe, H., Matsumoto, K. (2007). Effects of manganese complexes of curcumin and diacetylcurcumin on kainic acid-induced neurotoxic responses in the rat hippocampus. Biological and Pharmaceutical Bulletin, 30, 1732-1739. http://dx.doi.org/10.1248/bpb.30.1732

Sumanont, Y., Murakami, Y., Tohda, M., Vajraguptam, O., Watanabe, H., Matsumoto, K. (2006). Prevention of kainic acid-induced changes in nitric oxide level and neuronal cell damage in the rat hippocampus by manganese complexes of curcumin and diacetylcurcumin. Life Sciences, 78, 1884-1891. http://dx.doi.org/10.1016/j.lfs.2005.08.028

Swamy, M., Sirajudeen, K. N., Chandran, G. (2009). Nitric oxide (NO), citrulline-NO cycle enzymes, glutamine synthetase, and oxidative status in kainic acid-mediated excitotoxicity in rat brain. Drug and Chemical Toxicology, 32 326-331. http://dx.doi.org/10.1080/01480540903130641

Szaroma, W., Dziubek ,K., Greń, A., Kreczmer, B., Kapusta, E. (2012). Influence of the kainic acid on antioxidant status in the brain, liver and kidneys of the mouse. Acta Physiologica Hungarica, 99, 447-459. http://dx.doi.org/10.1556/aphysiol.99.2012.4.9

Vincent, P., Mulle, C. (2009). Kainate receptors in epilepsy and excitotoxicity. Neuroscience, 309-323. http://dx.doi.org/10.1016/j.neuroscience.2008.02.066

Wang, Q., Yu, S., Simonyi, A., Sun, G. Y., Sun, A. Y. (2005). Kainic acidmediated excitotoxicity as a model for neurodegeneration. Molecular Neurobiology, 31, 3-16. http://dx.doi.org/10.1385/mn:31:1-3:003

Wefers, H., Sies, H. (1983). Oxidation of glutathione by the superoxide radical to the disulfide and the sulfonate yielding singlet oxygen. European Journal of Biochemistry,137, 29-36. http://dx.doi.org/10.1111/j.1432-1033.1983.tb07791.x

Yu, J., Zhou, C. Z. (2007). Crystal structure of glutathione reductase Glr1 from the yeast Saccharomyces cerevisiae. Proteins. 68, 972-979. http://dx.doi.org/10.1002/prot.21354

Zheng, S., Yumei, F., Chen, A. (2007). De novo synthesis of glutathione is a prerequisite for curcumin to inhibit hepatic stellate cell (HSC) activation. Free Radical Biology and Medicine, 43, 444-453. http://dx.doi.org/10.1016/j.freeradbiomed.2007.04.016
Zheng, X.Y., Zhang, H. J., Luo, Q., Zhu, J. (2011). Kainic acid-induced neurodegenerative model: potentials and limitations. Journal Of Biomedicine And Biotechnology, doi: http://dx.doi.org/10.1155/2011/457079
$10.1155 / 2011 / 457079$. 